\title{
A MODERNIDADE ARGENTINA E OS SISTEMAS FORMAIS FRANCESES *
}

Maria Lúcia Bastos Kern **

$\mathrm{O}$ presente trabalho tem como objetivo a análise da modernidade pictural na Argentina, nos anos 20 e 30. Para tal, vai-se limitar ao estudo das obras dos artistas que desenvolvem sua formação artística em Paris, na década de 20 , época em que os discursos teóricos e plásticos versam, em parte, sobre o "retour à l'ordre". É de interesse deste artigo analisar também a contradição, à primeira vista perceptível, entre a busca de renovação dos argentinos e a absorção de sistema de signos oriundos da tradição clássica humanista. Para isto, deve-se apreciar a modernidade pictural e o sentido que esta assume em relação ao sistema formal precedente, bem como as condições sócio-culturais em que esta se produz na sociedade argentina.

Primeiramente, torna-se necessário o estudo do "retorno à ordem" na França, como ruptura com parte das conquistas das vanguardas históricas e, ao mesmo tempo, como manutenção de signos de modernidade por estas elaborados, aliados à representação visual tradicional.

$\mathrm{O}$ "retorno à ordem" não é gerado pela 1 ạ Guerra Mundial, mas vem sendo produzido no interior das próprias vanguardas, no chamado período heróico (1905-1914). No entanto, não se pode negar que as atrocidades da guerra e a participação de muitos artistas nestas, tenham possibilitado a reflexão e a reavaliação de suas funções na sociedade, conduzindo, deste modo, à relaboração teórica e prática da pintura.

$\mathrm{O}$ "retorno à ordem" começa a ser elaborado dentro do próprio cubismo, pois este revoluciona com a concepção de arte dominante, ao se propor como "realismo plástico". Isto significa criar "fatos picturais", a partir da produção da realidade através de signos inventados pelo artistas, rompendo deste modo com a descrição da realidade por meio da pintura. ${ }^{1}$ Há uma mudança ideológica que não é aceita pela crítica de arte e, em geral, mal compreendida pelo público. 
Além desta revolução em torno dos valores que norteiam a arte, o cubismo enfatiza o trabalho artesanal na era da industrialização e da tecnologia, ao adotar a colagem de materiais simples a partir de um processo manual. Desmistifica a arte e ao mesmo tempo dá a esta uma certa autonomia em relação ao real, terminando assim por produzir mudanças nas relações entre obra e espectador. Com isto, uma série de críticas são feitas não só na França, mas em outros países europeus, como por exemplo na Alemanha. Ao ser rejeitado e objeto de severas acusações - como a do deputado francês Jules-Louis BRETON, que afirma que o clubismo poderia "comprometer nosso maravilhoso patrimônio artístico", este é banido num momento de fortes nacionalismos. ${ }^{2}$

Se de um lado,p cubismo provoca polêmicas, por outro, ser cubista é ser moderno. Numa época em que o mercado de arte floresce, graças, em parte, à ideologia do novo e do original, o cubismo começa a ter cada vez mais seguidores. Muitos destes começam a construir formas geométricas presas à realidade visual, motivados pela formação acadêmica e pelas acirradas críticas ao novo sistema visual. Outros são conduzidos ao gosto pela arquitetura devido ao andamento de suas próprias pesquisas.

Picasso, por exemplo, em 1915 pinta o retrato de Max Jacob, utilizando tanto procedimentos do cubismo, como da tradição clássica humanista.

A difusão da pintura construída e ordenada pelo desenho geométrico leva Apollinaire, antes do Salão de Outono de 1912, a afirmar que "Não há neste ano o aspecto de campo de batalha que havia em 1907, em 1908 e no último ano (...)". E o crítico Gustave Kahn destaca que depois do Salão dos Independentes

"Os cubistas encontraram a solidez dos planos e a sobriedade da cor (. . .). Uma das maiores dificuldades das fórmulas novas é de se adaptar a uma verdadeira transcrição da figura humana; os cubistas a conseguiram (...)". ${ }^{3}$

Percebe-se que a situação de conflito diminui graças ao desenvolvimento de um cubismo moderado, que passa a ser praticado de forma quase unânime.

Deve-se destacar também que em 1912 aparece o livro de Albert Gleizes e Metzinger, "Du Cubisme et des moyens de le comprendre", no qual os autores cristalizam em uma doutrina aspectos desenvolvidos nas pesquisas de Picasso e Braque.

A partir desta publicação começa paulatinamente a difusão de princípios normativos baseados no classicismo francês, nas pesquisas de Cézan- 
ne e no cubismo. Este sofre uma reeleitura, que o modifica profundamente, visto que é introduzido na pintura um processo de ordenação que tem como suporte cânones tradicionais, bem como a retomada da aparência visual.

O fenômeno da busca de ordenação e da aparência visual foi objeto de pesquisa não só dos criadores e seguidores do cubismo, mas também de artistas, como Matisse, Derain, Bonnard e Othon Friesz.

Segundo Jean Clair, os artistas herdeiros do pós-impressionismo (Bonnard), do fovismo (Matisse) e do cubismo (Lhote, Metzinger), todos se inscrevem numa determinada história. ${ }^{4}$ Esta seria a do retorno à tradição clássica nacional que ocorre não só na França, mas também na Itália e outros países europeus.

A revalorização desta tradição e das pesquisas de Cézanne, aliada a determinados procedimentos cubistas, como a construção geométrica, são elementos que compõem o discurso do "retorno à ordem". Isto é, a volta à disciplina, aos princípios da harmonia e do equilíbrio, ao "beau-metier", aos valores "eternos da arte", clássicos considerados universais.

A obseção pela disciplina, pela ordenação e pelos valores estáveis e perenes está de certo modo relacionada às mudanças que estão ocorrendo na estrutura econômica e política das sociedades européias.

A crise do liberalismo e a violência da guerra "revelam os valores ameaçados, bem como possibilitam a reflexão sobre as vanguardas e suas ações de destruição/construção (...)". 5

A multiplicidade de experiências e de pensamentos começa a preocupar a intelectualidade. Paul Valéry, por exemplo, destaca em "Crise de l'esprit"

"que a desordem se encontra de forma difusa e que esta se caracteriza pela livre coexistência em todos os espiritos cultivados, das idéias as mais disparatadas, de principios de vida e de conhecimentos os mais opostos". ${ }^{6}$

Os movimentos de vanguarda enquanto questionadores de valores estáveis do passado e como propostas diferenciadas voltadas para o presente e futuro; a livre iniciativa; o culto do novo, da originalidade e do individualismo são objetos de reflexão e de transformação. Estes valores passam a ser considerados como geradores de instabilidade e de ameaça social.

A nova ordem é contra o individualismo, a multiplicidade, o materialismo e a pesquisa constante do novo. Projeta um sistema visual mais homogêneo, voltado aos valores espirituais e perenes, bem como a criação coletiva e a retomada de técnicas e habilidades artesanais próprias à arte humanista. 
“A crise é regeneradora, ela conduz aos verdadeiros valores, às origens e o discurso estético se alimenta desta 'filosofia' de ordem moral, propondo naturalmente o retorno à tradição depurada, à Natureza soberana esquecida durante os anos de abundância".?

Apollinaire ao publicar o seu livro "Les peintres cubistes" em 1913, destaca que a "pintura se purifica no Ocidente, com esta lógica ideal que os pintores antigos transmitiram aos novos (...)". ${ }^{8}$ Mais adiante ele afirma que é "necessário aos novos artistas uma beleza ideal que não seja mais somente a expressão orgulhosa da espécie, mas a expressão do universo, na medida em que é humanizado (...)".9

Apesar de Apollinaire ter sido um dos poetas mais entusiasmados com as revelações da pintura cubista e ter aderido ao movimento, percebese nesta sua obra um pensamento artístico voltado aos ideais da tradição clássica, antes da 1 ạ Guerra.

Portanto, não é a guerra que gera a mudança em si, visto que esta vem se produzindo no interior da própria vanguarda, motivada, em parte, pelo choque do novo e pela insegurança frente ao mesmo. Isto é, a destruição de um sistema visual instituído desde a Renascença e a imposição de outro, que aporta diferentes valores ideológicos. Fenômeno de transformação revolucionária que também condiciona certos marchands a estimularem os artistas a manutenção de um cubismo mais conservador.

A arte como produto cultural de uma sociedade não é gerada pelos valores desta, mas ela participa no processo de elaboração destes valores, aceitando-os ou negando-os.

Gino Severini, por exemplo, publica em 1921, em Paris o livro "Du cubisme au classicisme", com substítulo "Esthétique du compas et du nombre", no qual ele endossa os valores de ordem da tradição clássica humanista em oposição à multiplicidade de experiências individuais realizadas pelas v́anguardas. Nesta.obra, ele afirma que no começo do século $\mathrm{XX}$ reinava a anarquia artística, gerada por questões de ordem moral e social. "Depois da Renascença Italiana, as leis construtivas são gradualmente esquecidas", pois o artista se preocupou em "exprimir e afirmar sua individualidade, fora de toda regra ou método". ${ }^{10}$ A procura excessiva da "originalidade", leva o artista ao "isolamento da coletividade". Este "foi o primeiro passo para a decadência". 11

Percebe-se nesta exposição do pensamento do autor a crise que vive o artista moderno, num momento de dissolução dos ideais liberais e de reelaboração de diferenciados projetos ideológicos. $\mathrm{O}$ artista produz a pintura e a teoria da mesma, tendo como fìm divulgar a sua solução para a crise. 
Além de Severini diagnosticar os problemas da arte moderna, ele propõe um método baseado na estreita relação entre arte, ciência e as eternas leis oriundas da Renascença. Método que permite uma certa homogenização da produção artística e uma função social mais ampla, já que possibilitaria a compreensão de um público maior.

Ele finaliza o seu livro afirmando que "a grande idéia condutora dos humanistas era esta sintese entre a ciência, a arte e a filosofia, que conduz à unidade de concepção e de representação universal", ${ }^{12}$ devendo, assim, esta idéia ser condutora da arte na atualidade.

O "retorno à ordem" é também divulgado em 1912 na exposição denominada "Seccion d'Or", bem como através da "Nouvelle Revue Française", criada em 1919 por Jacques Rivière tendo como fim "fazer prever uma renascença clássica". ${ }^{13} \mathrm{O}$ crítico de arte desta revista, André Lhote, difunde seu pensamento sobre a estética do "retorno à ordem", diferenciando o cubismo francês (o seu) - dos seus seguidores e companheiros do cubismo espanhol (Picasso, Juan Gris e Diego Rivera). ${ }^{14}$

A volta à tradição é também objeto de reflexões teóricas de Le Corbusier e Ozenfant, criadores do Purismo, cujas idéias são divulgadas através de seus livros ${ }^{15}$ e da Revista "L'Esprit Nouveau".

Para o presente estudo, é necessário analisar suscintamente as idéias de um dos principais teóricos, André Lhote, já que este em sua Academia as transmitiu aos artistas latino-americanos e, sobretudo, argentinos.

A sua importância é tal que em 1924, o crítico de arte, Waldemar George destaca:

"André Lhote ocupa uma posição central entre o cubismo e o naturalismo. Suas teorias, seu ensinamento, seu método de trabalho o classificam entre os pintores cuja influência tem um papel determinante na evolução da arte contemporânea". ${ }^{16}$

Para Lhote, "teoricamente (. . .) o cubismo tende a se a proximar da linha tradicional, trazendo para o plano plástico as preocupações (...) sobre o plano colorido. $A$ cor submetida à forma, é com efeito a primeira virtude de uma pintura clássica". ${ }^{17}$ Mas para o autor "isto não é suficiente; é necessário por sua vez que a forma seja submetida a um ritmo geométrico, como o ensinamento de Vinci, Rafael e Poussin. Desde então, as descobertas sensiveis aos pintores não serão abandonadas sobre a tela em estado bruto (...), mas serão submetidas à uma refundição total e organizadas segundo as regras da composição tradiconal". ${ }^{18}$ 
Ele acredita que as formas são vivificadas e purificadas pela geometria e quando submetidas às leis físicas de equilibrio, isto é, ao uso de horizontais e verticais. ${ }^{19}$

Em 1917, no artigo "De la composition classique", Lhote afirma que é necessário submeter o "quadro ao ritmo" de "um edifício"20, isto é, à ordenação e à construção.

Para ele, "a ordem se exprime pelas leis; plasticamente, estas leis se exprimem pela geometria (...)".21

Em artigo posterior (1922), "Seurat", escrito para a revista "Valori Plastici" ele define o que vem a ser a construção:

"dar mais solidez ao desenho, mais corpo aos objetos, tornar mais pesado que a natureza deste (. . .) material (...). A arte da construção pictural será assim (...) uma ressurreição do naturalismo (...)". ${ }^{22}$

Mas é claro, de um naturalismo submetido ao rigor das leis clássicas, pois a natureza, segundo Lhote, "tem sempre a tendência a voltar ao $\operatorname{caos}(\ldots)$ "..$^{23}$

No entanto, ele acredita que o rigor em relação à construção e a ordenação não impedem a emoção plástica e o lirismo, visto que a construção significa também "permitir que os nossos anjos interiores se evadam com maior facilidade". ${ }^{24}$

Para o teórico e artista francês, a arte não deve ser uma mera cópia da natureza, mas ponto de partida para a invenção. Este é um dos motivos de Lhote ter tanto admirado Cézanne. A seu ver a

"descoberta essencial de Cézanne é que (. . .) substituiu cada objeto real por signos nascidos deste, cujo conjunto não poderá em algum ponto coincidir com o objeto em questão". 25

Em outra publicação ele destaca que "esta operação (. . .) consiste em significar no lugar de imitar (...)". ${ }^{26}$

Apesar de Lhote se afirmar como representante do verdadeiro cubismo francês, ele não consegue fugir do "cezannismo" dogmático em oposição ao cubismo espanhol. Dogmatismo que era condenado por Cézanne, pois ele acreditava que o uso da teoria pré-existente à obra, a dirigiria de forma abstrata e ocultaria as realidades do objeto e da própria obra. ${ }^{27}$

Lhote ao reduzir o cubismo a princípios e leis clássicas rígidas, condena ao extermínio a conquista do "fato picutral" isto é, a criação de signos inventados pelo artista, tendo em vista a constituição de uma realidade autônoma. 
Se de um lado, as suas teorias se apóiam em Cézanne e em alguns elementos do cubismo, como a construção geométrica; por outro, elas encontram, sobretudo, sustentação nos clássicos franceses, como Poussin, Ingres, Lorrain, pelo gosto da arquitetura, do "beau-métier" e da ordenação rigorosa.

A adoção do classicismo peculiariza-se assim, pela pesquisa e absorção de diferentes fontes reperáveis da história da arte francesa - do renascimento ao neoclassicismo e posteriormente, de Cézanne e do cubismo como uma espécie de busca de identidade entre a sociedade do passado e a sociedade moderna. A recuperação dos valoes e signos da tradição (como o fazer artesanal e o gosto pela arquitetura) e a consequente reelaboração, possibilita a montagem de um sistema visual que venha solucionar, em parte, a crise do artista moderno, bem como reforçar os valores conservadores dominantes.

A retomada da tradição nacional tem como fim também a elaboração de um sistema visual baseado na constituição rigorosa de um espaço plástico homogêneo em oposição ao individualismo e ao materialismo precedentes. Representa, de um lado, a tentativa de unidade e, do outro, a procura de reaproximação com o público e de uma função social mais efetiva, já que a arte é concebida como portadora de valores perenes e de uma ordem moral.

Outro artista que deve ser considerado no presente estudo é ÉmileOthon Friesz, pelo fato de ter orientado alguns pintores argentinos, que passaram antes pelos ensinamentos de Lhote.

Friesz é procurado pelos argentinos por ser, na época, um artista bastante reconhecido pelo seu trabaho, bem como pela ausência de dogmatismo.

Como um dos "criadores do fovismo", ele afirma que eles mesmos foram os primeiros a chaciná-lo, pois "a cor deixa de ser a condutora da tela", quando "o desenho renascia sob volumes e luz (...)" ${ }^{28}$ Isto ocorre no momento em que a construção geométrica é descoberta pelos cubistas, e que começa a ser praticada pelos "fauves".

Friesz tem uma formação baseada no estudo dos mestres clássicos, como a grande maioria dos artistas de sua geração. Insatisfeito, procura descobrir o processo de pesquisa efetuado por Cézanne, Gauguin e Van Gogh.

Ele não imita, mas medita sobre os resultados das experiências de Cézanne, buscando a atitude do mestre diante da natureza e não os seus procedimentos de execução, que foram objeto de cópia por grande parte dos artistas de sua época. ${ }^{29}$ 
Apesar de fazer uso intenso da cor arbitrária, buscando assim a pureza da paleta e a ruptura com a pintura narrativa, Friesz não abandona praticamente a construção formal. No entanto, esta aparece, freqüentemente, com o desenvolvimento do cubismo e principalmente nos anos 20 , quando „a ênfase é dada ao desenho.

Neste momento, Friesz retoma signos da tradição humanista, que geram o seguinte comentário:

"liberado de dogmatismo, constrói magistrais composif̧ões onde a verdade dos elementos (o mar, os céus) não deve ser traduzida às custas do rigor plástico e da qualidade pictural". 30

Diferentemente de Lhote, Friesz não produz teorias e textos críticos c apresenta uma postura frente à pintura, mais liberta de dogmatismos.

Para èle, é necessário admirar os grandes mestres do passado, porém, controladamente, para não seguir suas regras e seus procedimentos de modo rigoroso. ${ }^{31}$

Esboçado, em parte, o panorama da retomada da tradição clássica lıumanista na França, deve-se analisar, a seguir, a difusão da mesma na Argentina e os processos de incorporação e de reelaboração efetuados pelos pintores platinos nos anos 20 e 30 .

A divulgação da nova concepção estética é feita não só por André Lhote de modo dogmático, mas também por outros artistas como Gino Severini, Albert Gleizes, Metzinger, Bissière, Le Corbusier, etc. . . Para transmití-las, eles utilizam o discurso verbal - artigos, livros - o discurso oral - conferências - e o discurso plástico - exposição de suas obras e reprodução das mesmas em livros e revistas especializadas.

De um lado, as idéias destes artistas serão conhecidas na Argentina através de publicações de artigos de André Lhote, Le Corbusier, Apollinaire, Jean Cocteau, ${ }^{32}$ Maurice Raynal na revista "Martín Fierro" (1924/ 1927). ${ }^{33}$ Revista literária e artística que é criada com o fim de divulgar as novas concepções de arte que 'v̌igoram na Europa, tendo em vista terminar como o academicismo na Argentina. ${ }^{34}$

Por outro lado, as novas idéais estéticas penetram de forma mais efetiva neste país atrav́es dos artistas que fazem viagens de estudos à França. listes, repudiando o sistema acadêmico, procuram na Europa estudar com urtistas de renome em meio à produção moderna.

Os artistas argentinos absorvem as teorias em voga no centro hegetwònico internacional, por meio do ensino, da leitura de revistas especializadas e da apreciação de exposiçẽos e salōes em que estas estão presentes. 
Grande parte dos pintores argentinos que estudam em Paris, nos anos 20, seguem curso no ateliê de André Lhote, que é um dos mais concorridos neste momento.

Para este ateliê se dirigem Horácio Butler, Aquiles Badi, Hector Basaldúa, Lino Spilimbergo, Domínguez Neira e Antonio Berni. Todos incorporam a preocupação com a construção formal, estudando os mestres do passado no Museu do Louvre.

Esta busca de valores tradicionais como a ordem, a disciplina, a hierarquia, a espiritualidade em oposição ao excessivo individualismo e materialismo ocorre não só na Europa, mas também na Argentina.

Segundo depoimento de Horácio Butler:

"Spilimbergo estudava os primitivos italianos. Badi estava enamorado de Poussin. Basaldúa ia ao Louvre copiar um quadro de Veronese, eu havia descoberto a Piero de la Francesca. ..."35

O mesmo fenômeno de retomada da tradição clássica ocorre na Itália, possibilitando a Badi, Spilimbergo e Raquel Forner, que se estabeleceram neste país antes de residir em Paris, a estudar também os grandes mestres.

A valorização da arte nacional francesa é muito estimulada por Lhote, que afirma orientar os seus discípulos da seguinte maneira:

"Tendo estudado as regras da composição clássica, eu as ensino aos meus alunos. Eu lhes mostro tamberm aquelas do belo desenho articulado (...). Por que eu desejo lutar contra o desenho mole, invertebrado (...)". ${ }^{36}$

Isto ocorre aos pintores

"que não são submetidos à disciplina arquitetural, tal como entendiam os pintores franceses dos séculos XIV, $X V$ et $X V I$, que nós não admiramos jamais suficientemente as obras puras e tão humanas". ${ }^{37}$

Com Lhote, os artistas argentinos são conduzidos à disciplina e à construção, tendo como base a tradição humanista e eliminando, assim, o supérfluo e o efêmero, pois ele acredita que através do uso da arquitetura, como elemento ordenador, são mantidos os valores perenes da arte.

Nesta etapa do estudo, é necessário se analisar o momento sócio-cultural argentino, para se compreender melhor a adoção de princípios clássicos pelos artistas.

"Na segunda década do séuclo $X X$, o surto de nacio" nalismo é simultâneo à crise da estrutura social. Nesta 
época, alteram-se as antigas relações entre a sociedade rural e urbana, graças, em parte, à industrialização e urbanização, que possibilitam o crescimento do proletariado $e$ das novas classes médias". ${ }^{38}$

E um nacionalismo conflituoso, devido a coexistência de diversos nacionalismos, à dificuldade de integraçåo nacional, propiciada pela numerosa população de imigrantes estrangeiros, que não possuem um passado comum, e aos interesses divergentes de classes. ${ }^{39}$

Até o início do século $\mathrm{XX}$, os grandes proprietários rurais mantém hegemonia, mas ao se sentirem ameaçados frente às crescentes reivindicações do proletariado urbano, estes elaboram um nacionalismo agrário, contra o cosmopolitismo, os imigrantes estrangeiros e os movimentos sindicalistas, socialista e anarquistas. Esta variante de nacionalismo exalta o gaúcho como herói e as tradições culturais. A representação destes valores é efetuada na pintura pelo artista acadêmico Quirós.

Outro nacionalismo é produzido pelos políticos e intelectuais que representam os interesses dos trabalhadores. Ê um nacionalismo que se opбe à hegemonia dos grandes proprietários rurais e à dominação econômica estrangeira, tendo como objetivo a realização de reformas sociais.

A representação simbólica desta variante /de nacionalismo é executada pelos pintores e gravadores do Grupo Boedo, para os quais a arte deveria ser instrumento de ação política. Para que a pintura seja um instrumento eficiente é necessário usar formas de fácil compreensão, isto é, oriundas da tradição acadêmica. Os membros deste grupo ao defenderem esta concepção de arte, criam forte oposição à modernidade e à internacionalização da arte. ${ }^{40}$

Entretanto, com a crise do liberalismo na Europa e os efeitos desta sobre a economia argentina, assim como a crescente oposição à hegemonia dos grandes proprietários rurais, possibilitam o desenvolvimento de novas variantes de nacionalismo, baseadas nas idéias de intelectuais franceses, como Charles Maurras E J Jacques Maritain. É a partir destes nacionalismos que setores diferenciados da sociedade argentina divulgam valores de ordem, de hierarquia, de espiritualidade e de exaltação de determinadas tradições nacionais, contrários ao materialismo, ao individualismo e à liberdade.

Enquanto na Europa a retomada da tradição clássica se produz após a atuação das vanguardas e a constituição de novos sistemas visuais; na Argentina, esta tradição nunca desapareceu completamente, sendo a base da formação dos artistas em estudo. Além disso eles já convivem com uma ordem conservadora, não sendo novidade ao entrarem em contato com os 
nacionalismos franceses e com suas diferentes formas de representação simbólica.

Ao desenvolverem o estudo da construção nos termos clássicos, eles os fazem por estarem orientando suas pinturas nesta direção. Eles selecionam os mestres e o tipo de aprendizado que vão desenvolver, assim como os elementos formais que serão absorvidos, já que estes são muitas vezes as soluções plásticas buscadas para as suas pinturas.

Hector Butler afirma, por exemplo, que busca "a ordem e a construção", pois antes de residir na França, ele passa algum tempo na Alemanha, onde conheceu as pinturas de Cézanne, que o "seduziram de imediato". ${ }^{41}$ Esta deve ter sido uma das motivações de Butler para estudar com Lhote, visto que o mestre é um grande divulgador das experiências de Cézanne. Para o artista argentino, é a partir das lições de Lhote que "a construção cezanniana" se converte em elemento fundamental de "suas preocupaçôes". 42

Porém, não é apenas a busca da ordem e da construção formal que conduz Butler e outros argentinos a procurar orientação com André Lhote. Ele representa também a pintura "cubista" que para estes artistas simboliza a modernidade. Em carta escrita em 1923, Butler assim expressa esta questão:

"Sigo na Academia Montparnasse que, fora de dúvida é a mais interessante deste momento. (. . .) tenho tirado um enorme proveito. O professor, André Lhote, é um pintor muito discutido. (...) O Estudo que ali se faz está baseado no cubismo e numa série de principios que devem ser tomados como um meio e não como fim". 43

Se de um lado, o artista argentino vê no mestre a possibilidade de apreensão do novo, por outro, ele percebe que este é dogmático. Fato que o estimula, mais tarde, buscar orientação de Émile-Othon Friesz, com quem estuda três anos. ${ }^{44}$

Ainda sobre a questão da modernidade, Basaldúa dá outro depoimento que de certo modo complementa o de Butler.

"Paris me horrorizou; os quadros modernos careciam de sentido. Compreende-se. Levava comigo todo peso morto dos convencionalismos que haviam feito da pintura um acúmulo de formas mecânicas". ${ }^{45}$

A pintura de vanguarda causa impressão negativa no artista, conduzindo a escolher um mestre que ao preservar a tradição humanista, ele a concilia com elementos formais originários das produções de vanguarda. 
Nesta etapa do presente estudo, torna-se necessária a análise da pintura dos artistas argentinos que seguiram cursos com Lhote e Friesz, para se perceber os elementos do "retorno à ordem" que são absorvidos.

Porém, deve-se destacar que a observação e assimilação não se processam de modo passivo, isto é, de agentes ativos sobre receptadores passivos. Trata-se, antes de tudo, de selecionar os sistemas visuais e os seus valores que são pertinentes, aos valores pessoais dos artistas e do sistema sócio cultural, no caso argentino, dos quais estes são atores ativos.

Deve-se salientar que após a assimilação segue um processo de reelaboração. Este, nos países dependentes, está em geral aliado à questão de identidade cultural, como fator de distinção e, ao mesmo tempo, de ruptura com a arte acadêmica, pois esta não revela, em geral, preocupações com este tipo de problema.

A pintura de Butler durante sua estadia em Paris, baseia-se na construção geométrica, na qual os planos de luz e sombra e a linha contorno escura reforçam a sensação de volume sólido. Como, por exemplo, "Homem encostado" (1927); "Mulher sentada" (1929); e "Natureza morta" (1928).

Em "Composição mural” (1928), além do rigor da construção geométrica, as figuras monumentais estão dispostas no centro do quadro. $\mathrm{O}$ espaço pictural é hierarquizado e construído com auxílio da arquitetura, mantendo assim a estrutura da cena teatral, de origem clássica.

Apesar da construção geométrica exigir o despojamento e o abandono do supérfluo, em prol da medida e da ordem, Butler preserva, em parte, a descrição detalhista e a cena centralizada num primeiro plano, presa à aparência da realidade visual.

Durante três anos o artista estuda com Othon Friesz, executando neste período vários "nus femininos", como o seu mestre. O desenho continua sendo o elemento ordenador, mas agora aliado à cor, que é intensa $\mathrm{e}$ pura, sendo assim usada para modelar os volumes. Butler abandona a construção em planos geométricos, trabalhando mais a cor, como por exemplo, em "Flores com fundo vermelho" (1930); "Nú parado" (1928); "Nú junto ao mar" (1930); e "Nú encostad̆o" (1931).

Entretando, o artista mantém em muitas das suas pinturas, como "A viúva do capitaão" (1931), a figura centralizada na forma piramidal no primeiro plano, tendo a paisagem, como pano de fundo. Isto é, preserva a separação figura/fundo e a hierarquização do espaço plástico.

Basaldúa passa por uma trajetória semelhante a de Butler. Ele estuda inicialmente com André Lhote e Charles Guérin, e posteriormente com Friesz.

Percebe-se na sua pintura o uso essencial do desenho como fator de ordenação, enquanto os planos de luz e sombra acentuam o sentido arqui- 
tetural e a solidez dos volumes. Como por exemplo, no "Retrato do pintor Victor Pissarro" (1925).

Em "Acrobatas" (1926) a construção formal baseia-se não só no desenho, mas também na cor, que modela as figuras, e na linha contorno escura, como o seu mestre Friesz.

A pintura de Domínguez Neira, estrutura-se na construção de superfícies planas, que se sobrepõem, sendo a cor, as texturas e as estamparias (simulacros de papéis de parede) objetos de combinações minuciosas. A cor e a concentração do ornamento acentuam o caráter decorativo de suas naturezas mortas dos anos 20 , e mesmo posteriores.

Já Antonio Berni segue outra trajetória. É discípulo de Lhote, em 1926, e após de Friesz. Nesta época, pinta naturezas mortas, em que as figuras são modeladas pela cor.

Entretanto, o rigor do desenho e da construção formal vai se intensificando após a exposição retrospectiva de De Chirico, em Paris, em 1928.

No ano seguinte, mantém contatos com os artistas surrealistas - André Breton, Dali, Buñel - com Louis Aragon e Henri Lefvre, e começa a ler os tratados de Freud.

Paulatinamente, a pintura de Berni apresenta um sentido misterioso e melancólico, seja pela presença do insólito, seja pela arquitetura clássica que é elemento estruturador do espaço. As longas perspectivas e sombras, como em De Chirico, ao simbolizarem a cristalização do tempo acentuam o caráter misterioso. Caráter este que é intensificado pelo sistema de representação realista das figuras, às vezes, proporcionais ao espaço em que estão configuradas, como aparece em trabalhos efetuados após seu retorno à Argentina ("Primeiros passos", 1937 ; "Sol de domingo", 1941).

Outros artistas argentinos, Lino Spilimbergo e Aquiles Badi, residem primeiramente na Itália e depois em Paris. Ambos ao seguirem curso com Lhote são levados a pesquisar a construção formal dos mestres do passado mais distante, bem como em Cézanne e no cubismo. Percebe-se nas primeiras obras a arquitetura em planos geométricos, que vai sendo substituída progressivamente pelos volumes sólidos e, às vezes, monumentais. Como, por exemplo, "Paisagem de San Sebastiá Curone" (1928) de Spilimbergo. Aos poucos, as longas perspectivas e a arquitetura, as vezes, clássica, passam a estruturar o espaço do quadro; $\mathrm{e}$ as figuras recebem um tratamento escultural. Com se pode ver em "Verona" de Aquiles Badi e em "Meditando" de Spilimbergo.

Raquel Forner, em 1929, viaja primeiramente pela Itália e depois dirige-se a Paris, onde estuda com Othon Friesz até 1931. A sua pintura, neste momento, apresenta figuras de grandes dimensões, nas quais o gosto pela construção está presente. 
Estudos Ibero-Americanos, XIV(2) - 88

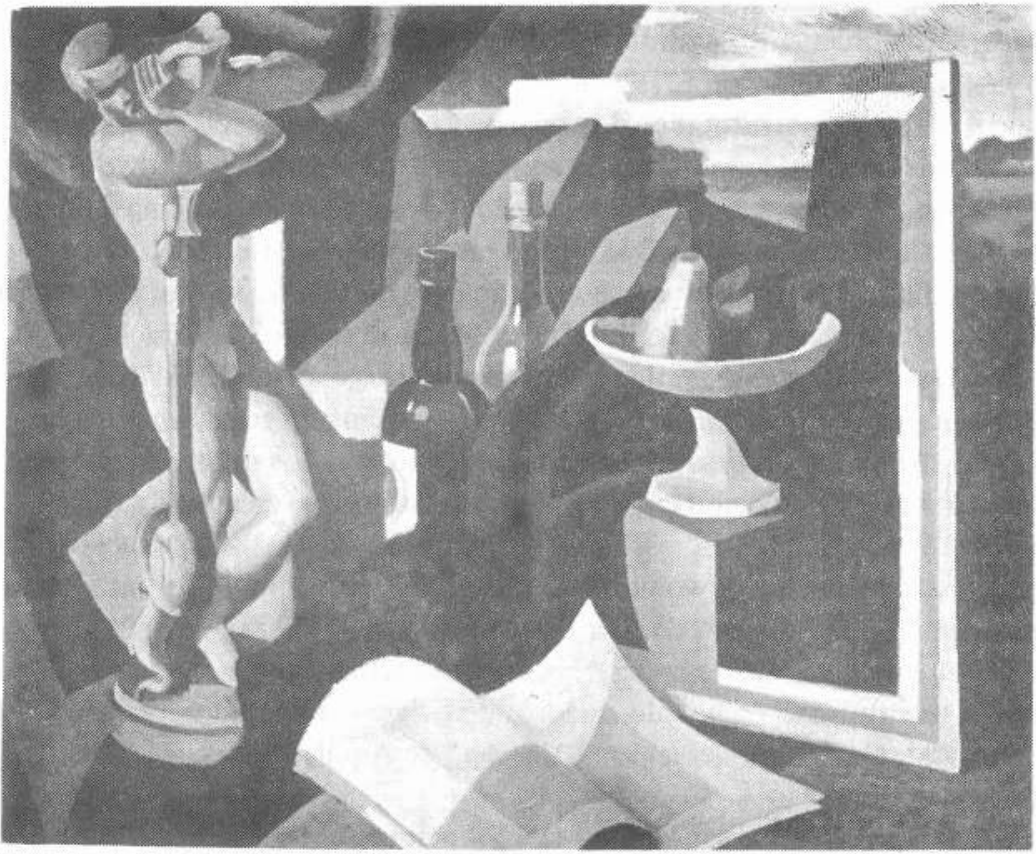

Domínguez Neira: "Natureza Morta", óleo, 0,80 x 0,95 m 


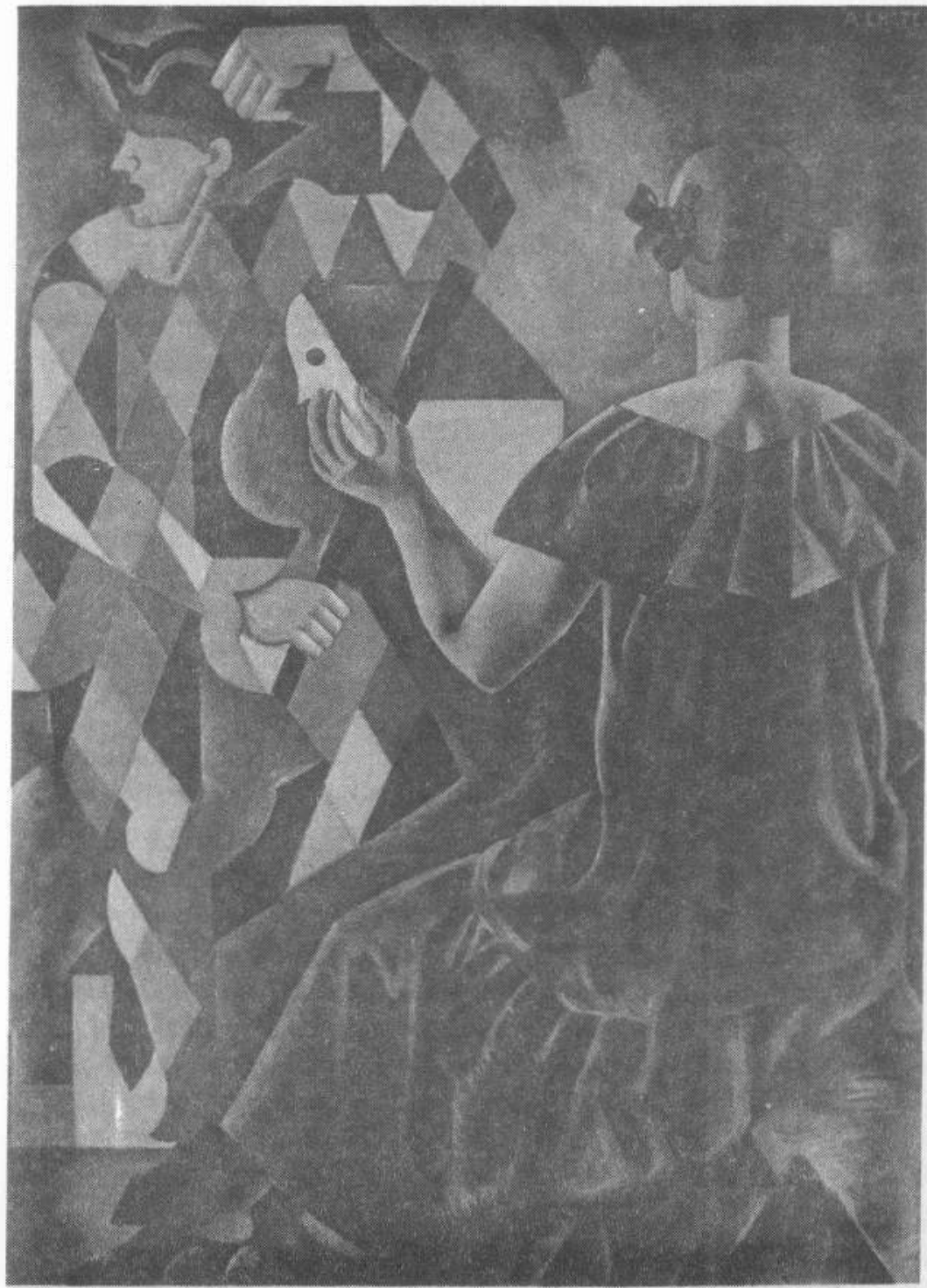

André Lhote, "Homenagem a Watteau", óleo, 116 × $89 \mathrm{~cm}, \mathrm{~s} / \mathrm{d}$. 
Durante o período de estudos no exterior, percebe-se nos trabalhos dos artistas argentinos declarada preocupação com o "métier", isto é, em conhecer técnicas e habilidades do passado e aliá-las aos procedimentos modernos.

A absorção de princípios teóricos distintos franceses - Lhote e Friesz - italianos do retorno à tradição clássica ${ }^{46}$ produz também obras diversificadas que têm em comum o gosto pelo fazer artesanal. Este, em verdade, nunca foi objeto de ruptura na arte argentina, como o foi na arte moderna européia.

Apesar da manutenção de signos da tradição, as obras dos artistas argentinos não são sempre bem recebidas no seu país, sofrendo, às vezes, severas oposições da crítica oficial.

Ao chegarem na Argentina eles são levados a reelaborar os sistemas visuais assimilados no exterior, sendo usual, neste momento, a pesquisa de signos concebidos como nacionais.

Butler, após período de crise profissional, propiciada pela não aceitação de sua pintura, começa a trabalhar junto ao Delta do Rio Tigre em Buenos Aires, local que havia vivido a sua infância.

Nas obras da série Delta, como "A despedida" (1938); “A embarcação" (1939) as figuras monumentais, segundo o artista, revelam a sua admiração por Piero de La Francesca. ${ }^{47}$ No entanto, não é apenas o aspecto monumental que permite perceber o gosto de Butler por este artista, mas também as formas volumosas e a estrutura dos quadros que é produzida através do jogo mesurado de linhas horizontais e verticais.

As figuras são frontalistas e apresentam traços étnicos indígenas. Tanto o frontalismo (usual nas representações indígenas), como o destaque do protótipo racial são evidências da preocupação do artista com a reelaboração de sua pintura de acordo com a tradição cultural argentina.

Além disto, Butler revela:

"Tratei de apoiar-me em algumas realidades de nosso clima, em certos aspectos caracteristicos do solo e da huz e em algumas sugestões poéticas de recordações (...) os rios, a lua ou as flores podem transformar-se em pintura nacional quando os observamos de forma particular". 48

A série "Delta" possibilita o estudo da "luz argentina", visto que as composições de Butler "estão baseadas em grandes setores de luz e sombra contrastados". Para ele, "esses são os fatores que definem a nacionalidade de uma pintura (...)".49

Será que as diferenças naturais, ao condiconarem o artista ao uso de cores mais luminosas e jogos de luz e sombra mais intensos, possibilitam a 
etiqueta de arte nacional?

De um lado, a afirmação do artista revela o seu condicionamento ainda à realidade visual; e por outro, talvez seja a solução para o reconhecimento de sua pintura, num momento em que as instâncias oficiais de arte estimulam a pesquisa de traços culturais argentinos e consagram a "arte nacional".

A idéia de arte nacional expressa por Butler é própria aos artistas latino-americanos que voltam da Europa e precisam criar distinções em suas pinturas, para dar a estas uma identidade cultural.

Antonio Berni retorna à Argentina em 1932, adere rapidamente ao Partido Comunista e redige com Siqueiros, Castagnino e Lázaro o "Exercício Plástico" (1933). Espécie de manifesto em prol dos novos recursos técnicos (câmara fotográfica, brocha mecânica), da ação coletiva, em oposição ao trabalho individual, e da pintura monumental exterior que "pertence as massas permanentes e flutuantes de uma urbe". 50

Berni ao adotar a pintura em grande formato e utilizar novos procedimentos mecânicos como a fotografia, busca romper com a "forma reprodutiva acadêmica". ${ }^{51}$ No entanto, se por um lado, o manifesto e a prática artística revelam signos de modernidade, por outro demonstram a manutenção de signos do passado clássico humanista, como por exemplo, a ordenação geométrica do espaço plástico.

Tanto nas telas de grandes dimensões como na pintura mural, a temática social está presente, como "Manifestação" (1934), "Desocupados" (1934) e "Chacareros" (1935). Nestas obras, a mudança fica evidenciada, pelo tratamento muralista que recebem. As figuras tornam-se monumentais e são agrupadas em geral no primeiro plano de modo que todas sejam visualizadas pelo público. Em "Manifestação" o destaque é dado às cabeças das figuras que representam o proletariado.

Berni para executar esta pintura, fotografou antes os tipos étnicos e as expressões de rostos de proletários urbanos argentinos, obtendo assim, através da ampliação, figuras de grande realismo.

As figuras nas obras de Berni dos anos 30, além de monumentais e rigorosamente construídas, são dispostas de forma frontalista. Elas encaram o espectador, com o fim de fazê-lo refletir sobre os problemas sociais.

O espaço pictural é hierarquizado e estruturado pela arquitetura clássica. Em "Chacareros", estes estão dispostos num cenário teatral de tradição humanista. $\mathrm{O}$ artista apresenta diversos tipos étnicos, sendo que os de origem indígena se salientam pelas suas diferentes posições no quadro, assim como a figura à cavalo (na extrema diretia), a mulher com a criança (no centro) que parece o menino Jesus dos primitivos italianos, e o autoretrato do artista (na extrema esquerda). Este contrasta em relação aos 
"Chacareros" pelo seu vestuário tipicamente burguês. A sua presença é signo de sua adesão às reivindicações das minorias sociais.

Tanto em "Manifestação", como em "Chacareros" o sistema de representação realista, baseia-se em princípios clássicos, apesar da introdução de procedimentos técnicos modernos. Percebe-se também a preocupação com o acabamento da pintura, fruto de seu aprendizado no exterior.

Em "Exercício Plástico", os autores manifestam a sua metodologia:

"Subordinamos a uma premissa básica da plástica pictória monumental, a uma lei clássica, analisamos previamente de maneira objetiva, por setores anatômicos, a estrutura geométrica (...). Criamos assim uma produção que também poderia denominar-se: "Caixa Plásti$\mathrm{ca},{ }^{52}$

Se por um lado, Berni preserva a estrutura pictural da tradição clássica para a representação temática social de forma mais realista, por outro, ele busca através deste sistema visual uma função educativa para a arte.

Num momento de crise do artista moderno, em que este se questiona sobre a validade do individualismo e sobre a função social do seu "métier", a pintura mural e de grande formato parecer ser a solução para Berni e seus companheiros. Solução que se baseia ainda na volta do ateliê coletivo, no qual a produção é coletiva, e no "beau-métier", combinados com os novos procedimentos mecânicos.

A pesquisa de tipos oriundos das minorias sociais argentinas, conduz Berni à busca e ao registro fotográfico dos indígenas e da arquitetura colonial. Em 1941, ele recebe uma bolsa da Comissão Nacional de Cultura para fazer estudos sobre as artes indígenas e colonial, no Peru, Equador e Colômbia.

Deve-se salientar que neste momento na Argentina os diferentes nacionalismos geram protestos contra o atrelamento político e econômico do país à Inglaterra, ou aos EUA e/ou ao bloco nazi-facista. No entanto, alguns destes nacionalismos fundamentam-se nas culturas indigenas précolombianas e mesmo na hispânica, como meio de procurar no passado nacional as raízes da verdadeira cultura argentina.

Berni e Spilimbergo executam pinturas murais na Galeria Pacífico encomendadas pelo Estado, bem como pinturas de cavalete, nas quais o retrato realista peculiariza-se pela forma escultória e pelo frontalismo das figuras. Estas ao terem seus movimentos cristalizados e serem solidamente construídas revelam um certo mistério. Como por exemplo, "La planchadora" (1936), e "Figuras" (1937). 
Raquel Forner retorna a Argentina, em 1931, e alguns anos mais tarde (1936) faz uma viagem ao norte de seu país e à Bolívia para pésquisar a cultura indígena. Frutos destes estudos aparecerão na série "Mulheres do mundo" (1937), seja pela frontalidade de algumas figuras, seja pelos traços étnicos. ${ }^{53}$

Tanto nesta série, como nas séries sobre a guerra Espanhola e a 2ạ Guerra Mundial, a artista procura expressar o drama humano e social. As suas figuras monumentais e solidamente construídas, em espaços pictóricos de tradição humanista, são extremamente expressivas. Como se pode observar em "A vitória" (1939) e "A queda" (1941). Daí sua afirmação: "Sempre tratei de dar aos meus quadros algo mais que uma intensão plástica". 54

Através deste depoimento de Forner e de sua obra, percebe-se que ela, como Berni e Spilimbergo, procuram uma função social mais ampla para os seus trabalhos, através de um sistema de representação compreensível para o grande público e que ao mesmo tempo estimule a reflexão.

Aquiles Badi, permaneceu na Europa de 1920 a 1936,período em que se estabelece na Itália e na França e que procura experimentar os ensinamentos dos mestres clássicos ao nível de concepção do espaço plástico, bem como aprender as técnicas de pintura mais usuais no passado, tais como a têmpera e o afresco.

Ao retornar a Buenos Aires, Badi preside a "Sociedade Argentina de Artistas Plásticos" e cria com Horácio Butler o "Atelier Libre de Arte Contemporáneo". Instituições que possibilitam aos artistas difundirem a arte moderna, ainda pouco aceita na capital argentina.

A pintura de Badi sofre transformações, apesar de manutenção de um certo rigor clássico. Inflamado pelo anti-fascismo, o artista começa a produzir uma pintura politizada, na qual a tragédia é representada através dos jogos internos de luz e sombra, como, por exemplo, "Descendimiento" (1937).

Em 1939, retorna a Itália e começa a trabalhar em pintura mural, buscando como os seus colegas, o contato com um público maior e uma certa independência do mercado da arte.

Hector Basaldúa regressa à Argentina em 1930, depois de ter viajado pela Itália. Desde 1928, o artista tem trabalhado com formas monumentais, como o "Beijo" (1929) e posteriormente "A italiana" (1932).

No período inicial de sua estadia, Basaldúa desenvolve uma temática voltada ao seu país - bairros e tipos sociais - em que a construção formal está quase sempre presente, aliada ao uso intenso da cor. ${ }^{55}$ Como, por exemplo, "Paisagem de Morón" e "Pátio em Morón". 
A modemidade picutal na Argentina, nos anos 20 e 30, não revela um caráter de ruptura muito acentuado e nem mesmo o sentido revolucionário deliberado. Essa se processa através da manutenção da tradição clássica, porém aliada a signos da modernidade. Isto é, às novas experiências que são realizadas, tendo como suporte algumas soluções plásticas do "retour à l'ordre" e as posteriores pesquisas de signos nacionais - tradições culturais primitivas e paisagem - são demonstrativas da intensão de mudança. Mudança que deveria se produzir moderadamente, visando romper com algumas normativas esclerosadas do academicismo em vigor e procurando dar à pintura novos significados e funções.

Apesar dos artistas argentinos voltarem da França praticando alguns procedimentos do "retorno"à ordem", estes são mal recebidos pelas instituições oficiais de arte - crítica e juri de salões - pela deliberada negação de certos valores acadêmicos. Dentre estes valores, poderia-se destacar o uso de cores arbitrárias, de formas monumentais, do frontalismo e aqueles que são oriundos da tradição rural argentina, que eram sacralizados através da pintura acadêmica e louvados pelos latifundiários em negação à modernidade urbana. A não aceitação das novas formas de representação é gerada, sobretudo, por divergências ideológicas, tanto ao nível de concepção de arte, como ao nível de nacionalismos.

A modernidade é controlada pelos nacionalismos vigentes no país, dentre os quais os artistas assumem posições diversas. Estes nacionalismos ao estabelecerem estreitos laços com o passado, criam identidade entre este, o presente e o futuro, controlando, assim, os processos de mudança e de renovação.

Além deste controle efetuado pelos diversos nacionalismos, dos quais alguns artistas são partidários, deve-se considerar que os mesmos coexistem, exaltando valores como a ordem moral, a disciplina, a hierarquia e a espiritualidade, que reforçam a nova concepção de pintura. Esta por sua vez também coopera na difusão destes valores na medida que se revela como renovadora, porém atrelada à tradição nacional.

Deve-se ainda salientar que o próprio sistema de arte não sofre, neste momento, mudanças tão significativas que condicionem a transformação revolucionária da pintura. ${ }^{56}$

Apesar da multiplicidade de pesquisas efetuadas pelos artistas argentinos, estas têm suportes semelhantes, visto que são oriundas da construção formal e da ordem clássica. A diversidade da pintura se encontra no uso de signos distintos da modernidade e na reelaboração personalizada da mesma.

No entanto, a pesquisa da tradição cultural indígena é produzida pela grande maioria de artistas, tendo em vista a reelaboração de nova pin- 
tura, seja a nivel de solução plástica (frontalidade e hierarquia), seja a nível de suporte cultural distinto do academicismo. Os artistas procuram, através destes meios, que as suas pinturas sejam portadoras de novos significados.

Enquanto a arte acadêmica mantém a herança clássica, valorizando desta o princípio de ordenação racional do desenho e negando a aceitação das culturas popular e primitiva; a nova pintura mantém os elementos ordenadores do classicismo aliados às conquistas modernas e a busca de significados distintos através destas culturas negadas pela arte precedente.

* A temática desenvolvida neste artigo foi objeto de comunicação apresentada pela autora no 460 Congresso Internacional dos Americanistas em Amsterdam, julho/ 1988.

\section{NOTAS}

1. LAUDE, Jean. "Art et Société en Europe 1906-1920". In: Proceedings of sixty International Congress of Aesthetics at Uppsala, 1966, p. 803.

As citações do presente estudo foram trauzidas pela autora do mesmo.

2. CABANNE, Pierre; RESTANY. L'avant-garde au XXème siècle. Paris, André Balland, 1969 , p. 117.

Após a 1a Guerra Mundial, o Estado Francês promove uma verdadeira liquidação de pinturas de vangaurda, sobretudo cubistas, que são adquíridas por colecionadores americanos. Ver LAURENT, Jeanne. Arts et pouvoirs. SaintEtienne, C.I.E.R.E.C., Université de Saint-Etienne, 1983. DAIX, Pierre. L'ordre et l'aventure. Paris, Arthaud, 1984.

3. DAIX, opus, cit., p. 105.

4. CLAIR, Jean. "Données d'un, problème". In: Les réalismes. Paris, Centre George Pompidou, 17 Déc. 1980 - 20 Avril 1981 , p. 8.

5. KERN, Maria Lúcia. "A pintura argentina: modernidade e tradição". Comunicação apresentada no III Congresso Brasileiro de História da Arte, São Paulo, USP, 1987, p. 2.

6. REYMOND, Nathalie. "Le rappel à l'ordre d'André Lhote". In: Le retour à l'ordre dans les arts plastiques et l'architecture 1919-1925. Saint-Etienne, C I.E. R.E.C., Univ. St. Etienne, 1975, p. 222.

7. CEYSSON, Bernard. "Peindre, sculpter dans les années 30 en France". In: L'art dans les années 30 en France. St. Etienne, Musée d'Art et d'Industire, marsmai 1979 , p. 22.

8. APOLLINAIRE, Guillaume. Les peintres cubistes. Genève, Pierre Cailler, 1950, p. 8 . 
9. APOLLINAIRE, opus cit., p. 27.

10. SEVERINI, Gino. Du cubisme au classicisme. Paris, Povolosky, 1921, p. 13.

11. SEVERINI, opus cit., p. 15.

12. SEVERINI, opus cit., p. 120.

13. REYMOND, opus cit., p. 210.

Em 1923, a revista "Valori Plastici" é traduzida para o francês com o título "Le neoclassicisme dans l'art contemporain", sendo ilustrada com obras de Braque e outros artistas.

14. Pergunta-se onde Lhote colocaria Braque nesta tipologia do cubismo? Segundo André Lhote, "um outro cubismo francês" para opor ao outro, aureolado de um misticismo espanhol (...).” Parlons Peinture, Denoél et Steele, 1936, p. 305 .

Percebe-se que a tipologia é oriunda de um pensamento dogmático nacionalista e que valoriza a razão, a construção geométrica despojada e a ordenação, pois o téorico francês critica neste mesmo texto o uso da colagem, que ele denomina de "materiahis or namentais", bem como o prática dos "arabescos".

15. O livro destes autores que melhor condensa suas idéias teóricas é La peinture moderne, Paris, G. Grès, 1925.

16. GEORGE, W. "L'amour de l'art", janv. 1924. In: COURTHION, Pierre. André Lhote. Paris, Nouvelle Revue Française, 1926, p. 14.

Deve-se destacar que o crítico Waldemar George mantém nesta época fortes relações com o fascismo e que se ocupa basicamente dos artistas italianos que vivem em Paris.

Lhote além de colaborador regular da "Nouvelle Revue Française", escreve artigos para "L'Esprit Nouveau" e revistas estrangeiras, como "Martín Fierro" de Buenos Aires; faz também conferências na Sorbonne, Collège de France e no exterior; e publica livros. A partir de 1920 é membro do comitê do Salão dos Independentes. Através destas múltiplas atividades, ele difunde as suas teorias sobre pintura e legitima as obras dos artistas que as seguem, isto é, os artistas que constituem o grupo do "cubismo francês".

17. LHOTE, A. Ecrits sur la peinture. Bruxelles, Lumière, 1946, p. 76.

18. LHOTE, opus, cit., p. 76.

19. LHOTE, A. Parlons peiture. p. 9.

20. LHOTE, A. opus, cit., nota 19, p. 6.

21. LHOTE, A. opus, cit., nota 19 , p. 6.

22. LHOTE, A. opus cit., p. 243. Em oposição à decomposição do objeto em planos geométricos que é própria do cubismo.

23. LHOTE, A. opus, cit., p. 6.

24. LHOTE, A. "Une exposition de Braque", Nouvelle Revue Française 69, Juin 1919. In: REYMOND, N. opus, cit., p. 217.

25. LHOTE, A. "Cézanne et la réalité de sensation". L'ARCHE 26, avril 1947, p. 126.

26. LHOTE, A. Peinture d'abord. Paris, Denoél, 1942, p. 18.

27. LAUDE, Jean. "Picasso et Braque, 1910-1914: la transformation des signes". In: Le cubisme. Paris, C.I.E.R.E.C., Univ. de St. Etienne, 1973, p. 19.

28. GAUTHIER, Maximilien. Othon Friesz. Genève, Pierre Cailler, 1957, p. 160.

29. SALMON, André. Emile-Othon Friesz. Paris, Nouvelle Revue Française, 1920, p. 13.

30. GAUTHIER, opus, cit., p. 151.

31. SALMON, André, opus, cit., p. 16. 
32. Jean Cocteau parece ter sido o primeiro a usar a denominação "Le rappel à l'ordre", quando pronuncia uma conferência no Collège de France em 1923 e que é publicada em 1926.

33. Editorial de 1926. In: PRIETO, Adolfo. El periodico Martín Fierro, B. Aires, Galerna, 1968 , p. 33.

34. A revista "Martín Fierro" publica no quarto número um manifesto no qual demonstra os seus objetivos:

"(...) Frente ao receituário que inspira as elocubrações de nossos mais "belos" espíritos e a afixação ao anacronismo e ao mimetismo que demonstram. Frente à ridícula necessidade de fundamentar nosso nacionalismo intelectual, criando valores falsos (...)

Martín Fierro sente a necessidade imprescindivel de definir-se e de chamar a todos que são capazes de perceber que estamos em presença de uma Nova sensibilidade e de uma Nova compreensão (. . . ) e novos meios e formas de expressão (...)

Martín Fierro se encontra, por isso, mais a gosto, em um transatlântico moderno, que em um palácio renascentista. (...)

Martín Fierro crê na importância do aporte intelectual da América (...) não significa, porém, que renunciaremos, nem muito menos, finjamos desconhecer que todas manhãs nos servimos de um dentifrício sueco, de umas toalhas da França e de um presunto inglês.

Martín Fierro tem fé (...) em nossa visão (...) em nossa capacidade digestiva e de assimilação. (. . .)" Borges e alii. Boedo y Florida. B. Aires, C.E.A.L., 1980 , p. 7-9.

35. VAZQUEZ, Maria Esther. Butler. B. Aires, Gaglianone, 1982, p. 94.

36. GUENNE, Jacques. Portrait d'artistes. Paris, Marcel Senheur, 1927, p. 190.

37. GUENNE, opus, cit., p. 190.

38. KERN, Maria L. opus, cit., p. 6.

39. RAMA, Carlos. Nacionalismo e historiografia en America Latina, Madrid, Tecnos, 1981, p. 16.

40. KERN, Maria L. opus, cit., p. 6-7.

41. VAZQUEZ, M. E. opus, cit., p. 66. Na Alemanha, o artista não se interessa pelo expressionismo, mas pelas pesquisas de Cézanne.

42. VAZQUEZ, M. E. opus, cit., p. 71.

43. VAZQUEZ, M. E. opus, cit., p. 71.

44. Bem como, Antonio Berni e Basaldúa.

45. MUJICA ĹAINEZ, Manuel. Hector Basaldúa. B. Aires, Losada, 1956, p. 9.

46. Na Itália, a revalorização da tradição clássica recupera fontes distintas da história da arte nacional: antiguidade romana, renascimento e neoclassicismo.

47. VAZQUEZ, M. E. opus, cit., p. 164.

48. PAYRO, Júlio. Butler, Emecé, 1954, p. 16-17.

49. VAZQUEZ, M. E. opus, cit., p. 104.

50. Antonio Berni. Obra pictórica 1922-1981, B. Aires, Museo Nacional de Bellas Artes, jun.-jul. 1984, p. 17-19.

51. Antonio Berni, opus., p. 18.

52. Antonio Berni, opus, cit., p. 18.

53. Com "Chola" recebe o prêmio da Comissão Nacional de Cultura em 1936. WHI-

THELOW, Guillermo. Raquel Forner, B. Aires, Gaglianone, 1980, p. 21.

54. WHTELOW, G. opus, cit., p. 14. 
55. Em 1933, Basaldúa é convidado a dirigir o setor de cenografia do Teatro Colón de Buenos Aires, cargo que exercerá durante quase toda sua vida e que the condicona a dar nova orientação ao seu trabalho.

56. As novas instituições de arte que lutam por um processo de renovação são: os críticos da revista Martín Fierro (1924/27) que apóiam as múltiplas experiências efetuadas pelos artistas argentinos; Associação Amigos da Arte (1924/ 46) que promove exposições da nova pintura e conferências; o "Nuevo Salon" (1927-31) que auxilia no processo de institucionalização da arte moderna; e as entidades de ensino criadas pelos artistas ao retornarem da Europa - "Atelier Libre de Arte Contemporáneo" (1932), no qual lecionam Alfredo Guttero, Domínguez Neira, Raquel Forner e o escultor Alfredo Bigatti; e o ateliê de mesmo nome criado por Aquiles Badi e Horácio Butler.

Deve-se salientar que apesar do surgimento de novas entidades, não há ainda o mercado de arte estruturado nos moldes atuais. As obras são adquiridas pelas instituições oficiais, quando premiadas em salões; são encomendadas ou compradas em exposições esporádicas.

\section{* * PONTIFICIA UNIVERSIDADE CATOLICA DO RIO GRANDE DO SUL CURSO DE PÓS - GRADUAÇĀO EM HISTORIA}

90620 PORTO ALEGRE - RS 